\title{
Fuzzy Time Series Theory Application for the China Containerized Freight Index
}

\author{
Ming-Tao Chou ${ }^{1}$ \\ ${ }^{1}$ Department of Aviation and Maritime Transportation Management, Chang Jung Christian University, Taiwan. \\ Corredpondence: Ming-Tao Chou, Department of Aviation and Maritime Transportation Management,Chang Jung \\ Christian University, Republic of China (Taiwan)No. 396, Chang Jung Rd. Sec.1, Kway Jen, Tainan 711101, Taiwan.
}

Received: March 4, 2016

Accepted:March 28, 2016

Available online: April 22, 2016

doi:10.11114/aef.v3i3.1568

URL: http://dx.doi.org/10.11114/aef.v3i3.1568

\begin{abstract}
China has evolved into one of the world's largest trading nations. China has adequate supply for imports and exports, and therefore, major shipping companies from various countries around the world all joined this market to perform freight transport. Currently, the main method of transporting goods is via shipping. China's containerized freight index (CCFI) is mainly used as a reference to evaluate the current freight tariffs standard. This study uses fuzzy time series to predict the CCFI. The results of our analysis found the following: 1. CCFI yield series has a volatility-clustering characteristic (the mean of the current yield is negative); 2. the R.M.S.P.E. (root mean square percentage error) value is $0.078 \%$, indicating that the goodness-of-fit of the model is quite good; 3 . future CCFI will be maintained at a low point of around 893.557, which is an optimistic long-term indication for freight; 4. currently, the supply of ships outweighs the demand, causing a long-term low CCFI. These four conclusions are hoped to serve as references for relevant policymakers in the future.
\end{abstract}

Keywords: Fuzzy, China's containerized freight index, Fuzzy time series

\section{Introduction}

Since 2000, the rise of China's economic strength in production and consumption has promoted vigorous growth in imports and exports; this has directly and indirectly benefited the Asian shipping industry, and they have began to flourish. Some international production and manufacturing companies have also transferred their factories to China. The substantial supply caused shipping companies to start to invest and merge together, hoping to obtain a share in Chinese transportation. Ships travel with the goods; it is the fundamental theory in the maritime industry. The location of the goods determines the fixed pointes where the ship will travel, including the production site and the transportation site. Goods produced by China must rely on many companies in the shipping and transport industry to perform the shipping task. During this period, China's container ports and harbors were improved to near perfection, showing that China can cope with the trend of the increasing large-scale transportation. In 2015, China alone accounted for seven out of the world's top 10 container ports, indicating the frequency and the large scale of China's imports and exports. World-renowned shipping companies over time have been involved in this area to take up contracts and shipping orders, causing the container trading volume to increase. On April 23, 1998, the China (Export) Containerized Freight Index (CCFI) was first compiled by China at the Shanghai Shipping Exchange (2015) to be used as the standard reference for freight on a regular basis. The CCFI is an important index for China's current regular shipping. With the development of regular shipping of container traffic, currently the largest consuming countries with major importing markets are in Europe and the US, and the biggest exporter is China (Hsiao et al., 2014). CCFI is obtained by taking the weighting share of the shipping cost for each company on the 14 shipping routes, and multiplying it with the weighting average of the total freight for the weighting share of each company at the port of discharge. The CCFI conveniently provides information on the market dynamics, as a reference to regular shipping markets, in order to understand the standard of the current freight cost (Xin, 2000).

Forecasting plays a very important role in the development of freight standards. As far as the government agencies are concerned, in addition to providing authorities with an important indicator in the planning and adjustment of economic development, CCFI forecasting is also used to indicate if the current condition is booming or not. Container shipping companies may use the possible future shipping standards to make reasonable planning decisions, and serve as a 
reference base for fleet planning and revenue management. For the public involved with transportation but without ships, they should also focus on the possible future freight standards and make adequate assessments in advance, before negotiating the number of shipping spaces with the shipping companies. Shipping companies should also pay attention to volume forecast and use it as a base reference for building new ships or establishing new alliances. Since the forecast for shipping standards is the base for a variety of economic planning, it is of great importance to choose the right forecasting tool. In addition to the benefits it offers governments and container carriers, forecasting can serve as a reference base for the public involved with transportation but without ships, and relevant transportation operators in conducting operational planning. If we can accurately analyze the current forecast and master the prediction for the public involved with transportation but without ships in the future, then it will be of great economic benefit for the above-mentioned industries in terms of planning and development.

The remainder of this article is organized as follows. Section 2 presents the definition and process of fuzzy time series In Section 3, the long-term predictive significance level definition is presented. The numerical example of the CCFI data is shown in Section 4. Finally, the conclusions are made in Section 5.

\section{The definition and process of Fuzzy time series}

The theory behind fuzzy sets, introduced by Zadeh (1965) in 1965, has been put towards a broad array of uses, such as fuzzy sets, fuzzy decision analysis, fuzzy regression, and fuzzy time series (Chen, 1996; Chen \& Hsieh, 2000; Chen, 2002; Chou, 2008; Chou, 2009; Chou, 2011; Chou \& Lee, 2006; Chen1996 ; Lee \& Chou, 2004; Liang et al., 2006; Liaw, 1997; Song \& Chissom, 1993a; Song \& Chissom, 1993b; Song \& Chissom, 1994; Song \& Chissom, 1997; Zadeh, 1965). This theory is also widely applied in the research and application of social science.. Since their introduction by Song and Chissom (Song \& Chissom, 1993a; Song \& Chissom, 1993b; Song \& Chissom, 1994; Song \& Chissom, 1997), fuzzy time series have been developed rapidly. Current fuzzy time series have benefited from both theory improvements and relevant applicable research (Chen, 1996; Chen, 2002; Chou, 2008; Chou, 2009; Chou, 2011; Chou \& Lee, 2006; Chen,1996; Lee \& Chou, 2004; Liang et al., 2006; Liaw, 1997; Song \& Chissom, 1993a; Song \& Chissom, 1993b; Song \& Chissom, 1994; Song \& Chissom, 1997; Zadeh, 1965), which has led to a greater diversity of use. This phenomenon indicates that the development of fuzzy time series has matured significantly. The definition and analytical procedure of fuzzy time series in this paper are demonstrated below:

Definition 1 A fuzzy number on the real line $\Re$ is a fuzzy subset of $\Re$ that is normal and convex. (Liang et al., 2006; Song \& Chissom, 1993a)

Definition 2 Let $Y(t)(t=\ldots, 0,1,2, \ldots)$, a subset of $\Re$, be the universe of discourse on which the fuzzy sets $f_{i}(t)$ $(t=1,2, \ldots)$ are defined and $F(t)$ is the collection of $f_{i}(t)(t=1,2, \ldots)$. Then, $F(t)$ is called a fuzzy time series on $Y(t)(t=\ldots, 0,1,2, \ldots)$. (Song and Chissom, 1993a; Song \& Chissom, 1993b)

Definition 3 Let $I$ and $J$ be the index sets for $F(t-1)$ and $F(t)$ respectively. If for any $f_{j}(t) \in F(t)$ where $j \in J$, there exists $f_{i}(t-1) \in F(t-1)$ where $i \in I$ such that there exists a fuzzy relation $R_{i j}(t, t-1)$ and $f_{j}(t)=f_{i}(t-1) \circ R_{i j}(t, t-1)$ where ' $\circ$ ' is the max-min composition, then $F(t)$ is said to be caused by only $F(t-1)$. Denote this as $f_{i}(t-1) \rightarrow f_{j}(t)$, or equivalently, $F(t-1) \rightarrow F(t)$. (Song \& Chissom, 1993a; Song \& Chissom, 1993b)

Definition 4 If for any $f_{j}(t-1) \in F(t)$ where $j \in J$, there exists $f_{i}(t-1) \in F(t-1)$ where $i \in I$ and a fuzzy relation $R_{i j}(t, t-1)$ such that $f_{j}(t)=f_{i}(t-1) \circ R_{i j}(t, t-1)$. Let $R(t, t-1)=\bigcup_{i j} R_{i j}(t, t-1)$ where $U$ is the union operator. Then, $R(t, t-1)$ is called the fuzzy relation between $F(t)$ and $F(t-1)$. Thus, we define this as the following fuzzy relational equation: $F(t)=F(t-1) \circ R(t, t-1)$. (Song \& Chissom, 1993a; Song \& Chissom, 1993b)

Definition 5 Suppose that $R_{1}(t, t-1)=\bigcup_{i j} R_{i j}^{1}(t, t-1)$ and $R_{2}(t, t-1)=\bigcup_{i j} R_{i j}^{2}(t, t-1)$ are two fuzzy relations between $F(t)$ and $F(t-1)$. If for any $f_{j}(t) \in F(t)$ where $j \in J$, there exist $f_{i}(t-1) \in F(t-1)$ where $i \in I$ and fuzzy relations $R_{i j}^{1}(t, t-1) \quad$ and $R^{2}{ }_{i j}(t, t-1) \quad$ such that $f_{i}(t)=f_{i}(t-1) \circ R_{i j}^{1}(t, t-1) \quad$ and $f_{i}(t)=f_{i}(t-1) \circ R_{i j}^{2}(t, t-1)$, then define $R_{1}(t, t-1)=R_{2}(t, t-1)$. (Song \& Chissom, 1993a; Song \& Chissom, 1993b) Definition 6 Suppose that $F(t)$ is only caused by $F(t-1)$ or $F(t-1)$ or $F(t-2) \ldots$ or $F(t-m)(m>0)$. This 
relation can be expressed as the following fuzzy relational equation: $F(t)=F(t-1) \circ R_{0}(t, t-m)$

This equation is called the first-order model of $F(t)$. (Song \& Chissom, 1993a; Song \& Chissom, 1993b)

Definition 7 Suppose that $F(t)$ is simultaneously caused by $F(t-1), F(t-2), \ldots$, and $F(t-m)(m>0)$. This relation can be expressed as the following fuzzy relational equation: $F(t)=(F(t-1) \times F(t-2) \times \ldots \times F(t-m)) \circ R_{a}(t, t-m)$. This equation is called the mth order model of $F(t)$. (Song and Chissom, 1993a; Song and Chissom, 1993b)

Definition $8 F(t)$ is a fuzzy time series if $F(t)$ is a fuzzy set. The transition is denoted as $F(t-1) \rightarrow F(t)$. (Chen, 1996)

Definition 9 Let $d(t)$ be a set of real numbers: $d(t) \subseteq R$. We define the exponential function and let

(1) $y=\exp d(t) \Leftrightarrow \ln y=d(t)$

(2) $\exp (\ln d(t))=d(t), \ln (\exp x)=d(t) \quad($ Chou, 2009)

Definition 10 The universe of discourse $U=\left[D_{L}, D_{U}\right]$ is defined such that $D_{L}=D_{\min }-s t_{\alpha}(n) / \sqrt{n}$ and $D_{U}=D_{\max }+s t_{\alpha}(n) / \sqrt{n}$ when $n \leq 30$ or $D_{L}=D_{\min }-\sigma Z_{\alpha} / \sqrt{n}$ and $D_{U}=D_{\max }+\sigma Z_{\alpha} / \sqrt{n}$ when $n>30$, where $t_{\alpha}(n)$ is the $100(1-\alpha)$ percentile of the $t$ distribution with $n$ degrees of freedom and $z_{\alpha}$ is the $100(1-\alpha)$ percentile of the standard normal distribution, that is, if $Z$ is a $N(0,1)$ distribution, then $P\left(Z \geq z_{\alpha}\right)=\alpha$. (Lee \& Chou, 2004)

Definition 11 Assuming that there are $m$ linguistic values under consideration, let $A_{i}$ be the fuzzy number that represents the ith linguistic value of the linguistic variable where $1 \leq i \leq m$. The support of $A_{i}$ is defined to be

$$
\left\{\begin{array}{l}
D_{L}+(i-1) \frac{D_{U}-D_{L}}{m}, D_{L}+\frac{i\left(D_{U}-D_{L}\right)}{m}, 1 \leq i \leq m-1 \\
D_{L}+(i-1) \frac{D_{U}-D_{L}}{m}, D_{L}+\frac{i\left(D_{U}-D_{L}\right)}{m}, i=m .
\end{array}\right.
$$

Definition 12 For a test $H_{0}$ :nonfuzzytrend against $H_{1}$ : fuzzytrend, where the critical region $C^{*}=\left\{C \mid C_{2}^{k}+C_{2}^{n-k}>C_{\lambda}=C_{2}^{n} \times(1-\lambda)\right\}$ and the initial value of the significant level $\alpha$ is 0.2. (Liaw, 1997)

Definition 13 [5] Let $d(t)$ be a set of real numbers: $d(t) \subseteq R$. An upper interval for $d(t)$ is a number b such that $x \leq b$ for all $x \in d(t) .{ }^{d(t)}$ is said to be an interval above if $d(t)$ has an upper interval. A number, max, is the maximum of $d(t)$ if max is an upper interval for $d(t)$ and $\max \in d(t)$.(Chou, 2011)

Definition 14 Let $d(t) \subseteq R$. The least upper interval of $d(t)$ is a number $\rightarrow \overrightarrow{\max }$ satisfying:

(1): $\rightarrow \overrightarrow{\max }$ is an upper interval for $d(t): x \leq \overrightarrow{\max }$ for all $x \in d(t)$.

(2): $\underset{\max }{\rightarrow}$ is the least upper interval for $d(t)$, that is $x \leq b$ for all $x \in d(t) \Rightarrow \overrightarrow{\max } \leq b$. (Chou, 2011)

Definition 15 Let $d(t)$ be a set of real numbers: $d(t) \subseteq R$. A lower interval for $d(t)$ is a number b such that $x \geq b$ for all $x \in d(t) . d(t)$ is said to be an interval below if $d(t)$ has a lower interval. A number, min, is the minimum of $d(t)$ if min is a lower interval for $d(t)$ and $\min \in d(t)$. (Chou, 2011)

Definition 16 Let $d(t) \subseteq R$. The least lower interval of $d(t)$ is a number $\stackrel{\leftarrow}{\min }$ satisfying: 
(1): $\overleftarrow{\min }$ is a lower interval for $d(t): x \geq \overleftarrow{\min }$ for all $x \in d(t)$

(2): $\overleftarrow{\min }$ is the least lower interval for $d(t)$, that is $x \geq b$ for all $x \in d(t) \Rightarrow \overleftarrow{\min } \leq b$. (Chou, 2011)

Definition 17 The long-term predictive value interval, $(\stackrel{\leftarrow \min , \max }{)})$ is called the static long-term predictive value interval. (Chou, 2011)

\section{The procedure of forecat}

The stepwise procedure of the proposed method consists of the following steps and a flow diagram is shown in Figure 1.

Step 1. Let $d(t)$ be the data under consideration and $F(t)$ be the fuzzy time series. Following Definition 11 , a difference test is used to understand whether or not the information is in a stable state. Recursion is performed until the information is in a stable state, where the critical region is $C^{*}=\left\{C \mid C_{2}^{k}+C_{2}^{n-k}>C_{\lambda}=C_{2}^{n} \times(1-\lambda)\right\}$.

Step 2. Determine the universe of discourse $U=\left[D_{L}, D_{U}\right]$.

Step 3. Define $A_{i}$ by letting its membership function be as follows:

$$
u_{A_{i}}(x)=\left\{\begin{array}{l}
1 \text { for } x \in\left[D_{L}+(i-1) \frac{D_{U}-D_{L}}{m}, D_{L}+\frac{i\left(D_{U}-D_{L}\right)}{m}\right) \\
\text { where } 1 \leq i \leq m-1 ; \\
1 \text { for } x \in\left[D_{L}+(i-1) \frac{D_{U}-D_{L}}{m}, D_{L}+\frac{i\left(D_{U}-D_{L}\right)}{m}\right] \\
\text { where } i=m ; \\
0 \text { otherwise. }
\end{array}\right.
$$

Step 4. Then, $F(t)=A_{i}$ if $d(t) \in \operatorname{supp}\left(A_{i}\right)$, where $\operatorname{supp}(\cdot)$ denotes the support.

Step 5. Derive the transition rule from period $t-1$ to $t$ and denote it as $F(t-1) \rightarrow F(t)$. Aggregate all transition rules. Let the set of rules be $R=\left\{r_{i} \mid r_{i}: P_{i} \rightarrow Q_{i}\right\}$.

Step 6. The value of $d(t)$ can be predicted using the fuzzy time series $F(t)$ as follows:

Let $T(t)=\left\{r_{j} \mid d(t) \in \operatorname{supp}\left(P_{j}\right)\right.$, where $\left.r_{j} \in R\right\}$ be the set of rules fired by $d(t)$, where $\operatorname{supp}\left(P_{j}\right)$ is the support of $P_{j}$.

Let $\overline{\operatorname{supp}\left(P_{j}\right)}$ be the median of $\operatorname{supp}\left(P_{j}\right)$. The predicted value of $d(t)$ is $\sum_{r_{j} \in T(t-1)} \frac{\overline{\operatorname{supp}\left(Q_{j}\right)}}{|T(t-1)|}$.

Step 7. The long-term predictive value interval for $d(t)$ is given as $(\stackrel{\min , \overrightarrow{\max }}{)}$.

Step8. Setup new triangular fuzzy numbers by $\Delta \mathrm{S}=(\stackrel{\leftarrow \min }{\hat{d}} \hat{d}(t), \overrightarrow{\max })$

\section{The Numerical example of the CCFI data}

In this paper, the number of columns authenticator China (Export) Containerized Freight Index (CCFI) provided by the Shanghai Shipping Exchange for this article. The CCFI reflects the spot rates of Shanghai export container transport market. CCFI objectively shows the container transport market and bridges China's shipping market to the world circle, which provides well-founded information to decision-makers of various shipping and trade enterprises as well as the governmental agency in charge of macro-economic regulation and control, thus attracting great attention of mass media and the related research and consulting institutes (Shanghai Shipping Exchange, 2015). The information for CCFI data was sourced from Shanghai Shipping Exchange (Shanghai Shipping Exchange, 2015), the historic data for which is 
defined in this article as CCFI, and information was collected on the season average data for the years 2010 Quarter 1 through 2015 Quarter 2. Over these 22 data points, analysis showed an average of 1080.563, with the standard deviation of 94.948 , a maximum value of 1283.458 and a minimum of 895.108 . From descriptive statistics, we can see that CCFI remain at the level of 1080.563. Compared to the figure from 2010 Quarter 1, this represents the peak level for recent years, and China's domestic demand remains weak, despite being affected by the global financial crisis and the European debt crisis. Therefore, weak domestic demand allows China's economic growth to remain attractive in the face of these negative impacts. For instance, June financial turmoil in the stock market in 2015. We discovered that, although China is significantly affected by its CCFI, the consequent adjustments also result in a synergetic change in the return rate of CCFI. As shown by Figure 1, CCFI have recovered from the impact of the financial crisis, and its current rate of return is negative. CCFI yield series has a volatility-clustering characteristic (the mean and its current rate of return is negative).

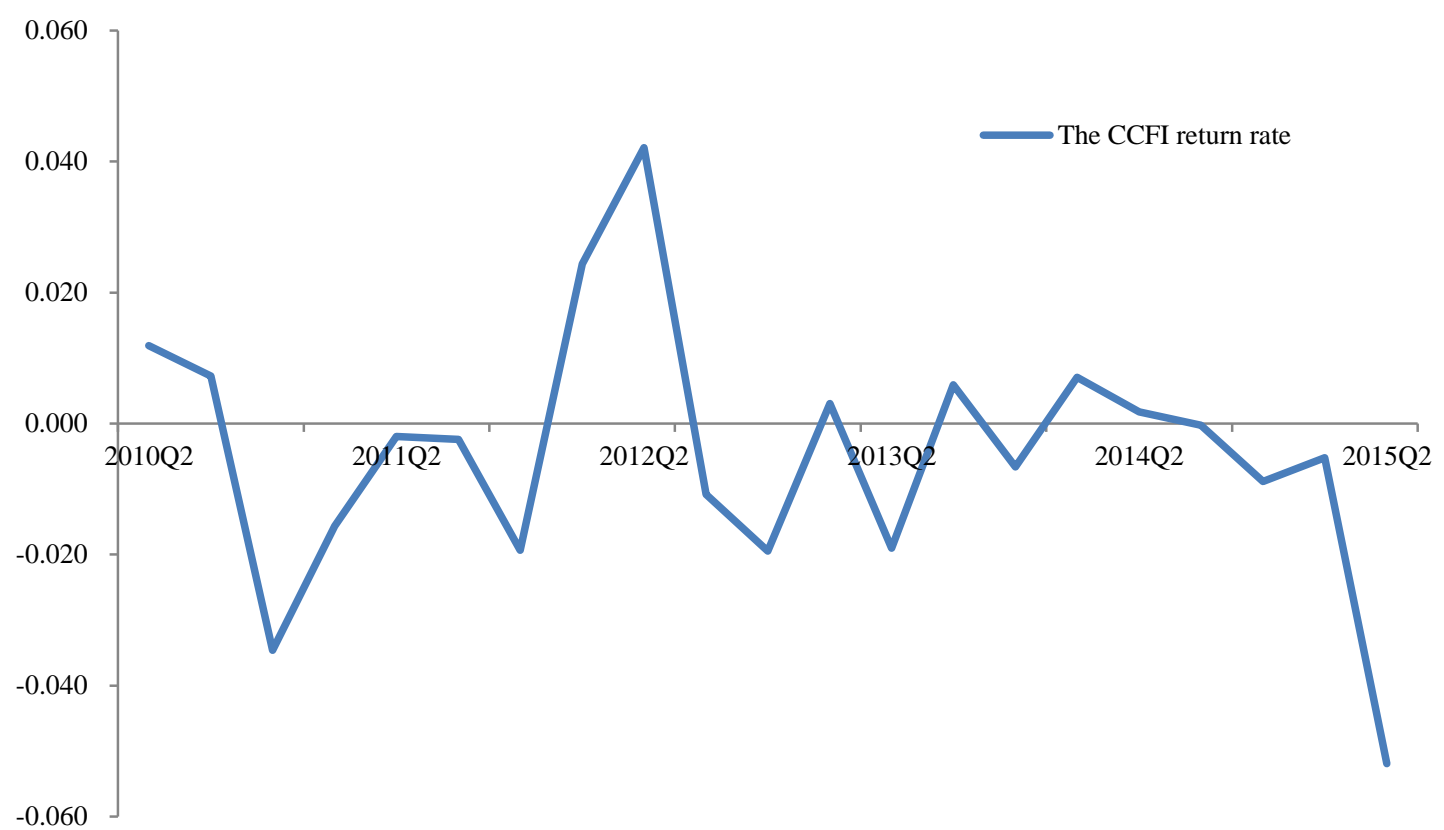

Figure 1. The rate of return of CCFI.

The following observation is made when using fuzzy time series to analyze the CCFI:

Step 1. First, we take the logarithm of CCFI data, as this helps to reduce the variation of data and improve the accuracy of the forecast. Therefore, let $C C F I(t)=\ln C C F I(t)$

Step 2. As maintaining stationary data while forecasting helps to improve the forecast quality, we conduct a stationary test on the CCFI data. For fuzzy time series, we can adopt a fuzzy trend test to measure whether CCFI's fuzzy trend moves upward or downward. Via this fuzzy trend test, we can convert the CCFI data into stationary series. If the original CCFI data present a fuzzy trend, we can then take the difference to eliminate this fuzzy trend. We then test again, after taking the first difference to measure if the CCFI data present a fuzzy trend. If a fuzzy trend is observed, we take the second difference, and so on.

Let $C C F I(t)$ be the historical data under consideration and let $F(t)$ be the fuzzy time series. Following Definition 11 , a difference test is used to understand whether or not the information is in a stable state. Recursion is performed until the information is determined to be stable. Once the region $=C^{\prime \prime}=\left\{C \mid C=C_{2}^{13}+C_{2}^{21-13}\right\}=106<\left\{C \mid C_{2}^{21} \times(1-0.2)\right\}=168$, the CCFI data is in a stable state and is not rejected.

Step 3. According to the interval setting of the CCFI data, we define the upper and lower bounds, which will help to divide the linguistic value intervals later. From Definition 10, the discourse $U=\left[D_{L}, D_{U}\right]$. From Table 1 , $D_{\min }=6.797, D_{\max }=7.157, s=0.008$, and $n=22$ can be obtained. Let $\alpha=0.05$. Since $n$ is less than 30, the Student-t distribution with 22 degrees of freedom is used as a substitute for the normal distribution. Thus, 
$t_{\alpha}(n)=t_{0.05}(22)=1.717, D_{L}=D_{\min }-s t_{\alpha} / \sqrt{n} \approx 6.765$, and $D_{U}=D_{\max }+s t_{\alpha} / \sqrt{n} \approx 7.189$. That is, $U=[6.765,7.189]$.

Step 4. After defining the upper bound and lower bound of the CCFI data in Step 3, we can define the range of CCFI by determining the membership function as well as the linguistic values. We also can define the range of sub-interval for each linguistic value.

Assume that the following linguistic values are under consideration: extremely few, very few, few, some, many, very many, and extremely many. According to Definition 11, the supports of fuzzy numbers that represent the linguistic values are given by:

$$
u_{A_{i}}(x)=\left\{\begin{array}{l}
1 \text { for } x \in[6.765+(i-1)(0.061), 6.765+i(0.061)) \\
\text { where } 1 \leq i \leq m-1 ; \\
1 \text { for } x \in[6.765+(i-1)(0.061), 6.765+i(0.061)] \\
\text { where } i=m ; \\
0 \text { otherwise. }
\end{array}\right.
$$

where $A_{1}=$ 'extremely few', $A_{2}$ ='very few', $A_{3}$ ='few', $A_{4}=$ 'some', $A_{5}=$ 'many', $A_{6}=$ 'very many', and $A_{7}$ ='extremely many'. Thus, the supports are: $\operatorname{supp}\left(A_{1}\right)=[6.765,6.826) \quad, \quad \operatorname{supp}\left(A_{2}\right)=[6.826,6.6 .886) \quad$, $\operatorname{supp}\left(A_{3}\right)=[6.886,6.947), \quad \operatorname{supp}\left(A_{4}\right)=[6.947,7.007), \quad \operatorname{supp}\left(A_{5}\right)=[7.007,7.068), \quad \operatorname{supp}\left(A_{6}\right)=[7.068,7.129), \quad$ and $\operatorname{supp}\left(A_{7}\right)=[7.129,7.189]$.

Step 5. According to the sub-interval setting of each linguistic value, we classify each historical data of CCFI into its corresponding interval in order to measure the corresponding value of the linguistic value for each interval.

The fuzzy time series $F(t)$ is given by $F(t)=A_{i}$ when $d(t) \in \operatorname{supp}\left(A_{i}\right)$. Therefore, $F(2010 Q 1)=A_{4}$, $F(2010 Q 2)=A_{5}, F(2010 Q 3)=A_{6}, \ldots$, and $F(2015 Q 2)=A_{1}$. A comparison between actual CCFI data and the fuzzy enrollment data is shown in Table 1.

Step 6. We apply fuzzy theory to define the corresponding value for the interval of each CCFI data, arrange the corresponding method of each CCFI data, and integrate the changes of all rules to determine the rules of CCFI quantity.

The transition rules are derived from Table 1 . For example, $F(2010 Q 1) \rightarrow F(2010 Q 2)$ is $A_{4} \rightarrow A_{5}$. All transition rules obtained from Table 1 are shown in Table 2.

Step 7. We calculate each rule by determining all the rules of CCFI, and the calculation results can be used to forecast future values.

The forecasting results from 2010Q1 to 2015Q2 are shown in Table 1.

Step 8. The calculated the CCFI rules can define the interval of CCFI data; using this interval we can then determine the variation of future long term intervals.

The long-term predictive value interval for CCFI is given as $(6.795,7.098)$. Thus the long-term predictive interval for CCFI is given as $(893.557,1210.121)$. Therefore the current long-term CCFI is bounded by this interval.

According to Step 8, the fuzzy CCFI of 2015Q2 shown in Table 1 is $A_{1}$, and from Table 2, we can see that the rules are the following fuzzy logical relationships in Rule 11 of Table 2, in which the current states of the fuzzy logical relationships are $\mathrm{A}_{1}$. Thus, the 2015Q3 CCFI predictive value is 893.557 .

Table 1. Fuzzy historical CCFI data and forecasted result

\begin{tabular}{cccc}
\hline Year & $\ln ($ Actual $)$ & Fuzzified & The forecasted value \\
\hline 2010Q1 & 6.995 & $\mathrm{~A}_{4}$ & 6.932 \\
2010Q2 & 7.031 & $\mathrm{~A}_{5}$ & 7.038 \\
2010Q3 & 7.090 & $\mathrm{~A}_{6}$ & 7.038 \\
2010Q4 & 7.000 & $\mathrm{~A}_{4}$ & 6.932 \\
2011Q1 & 6.954 & $\mathrm{~A}_{4}$ & 6.932 \\
2011Q2 & 6.914 & $\mathrm{~A}_{3}$ & 6.917 \\
2011Q3 & 6.895 & $\mathrm{~A}_{3}$ & 6.917 \\
2011Q4 & 6.832 & $\mathrm{~A}_{2}$ & 7.007 \\
2012Q1 & 6.881 & $\mathrm{~A}_{2}$ & 7.007 \\
2012Q2 & 7.157 & $\mathrm{~A}_{7}$ & 7.098 \\
2012Q3 & $\mathrm{A}_{7}$ & 7.098 \\
2012Q4 & 7.143 & $\mathrm{~A}_{5}$ & 7.038 \\
2013Q1 & 7.041 & $\mathrm{~A}_{5}$ & 7.038
\end{tabular}




$\begin{array}{llll}2013 \mathrm{Q} 2 & 6.971 & \mathrm{~A}_{4} & 6.932 \\ 2013 \mathrm{Q} 3 & 7.001 & \mathrm{~A}_{4} & 6.932 \\ 2013 \mathrm{Q} 4 & 6.947 & \mathrm{~A}_{4} & 6.932 \\ 2014 \mathrm{Q} 1 & 7.018 & \mathrm{~A}_{5} & 7.038 \\ 2014 \mathrm{Q} 2 & 6.990 & \mathrm{~A}_{4} & 6.932 \\ 2014 \mathrm{Q} 3 & 7.006 & \mathrm{~A}_{4} & 6.932 \\ 2014 \mathrm{Q} 4 & 6.945 & \mathrm{~A}_{3} & 6.917 \\ 2015 \mathrm{Q} 1 & 6.964 & \mathrm{~A}_{4} & 6.932 \\ 2015 \mathrm{Q} 2 & 6.797 & \mathrm{~A}_{1} & 6.795 \\ \text { transitions derived from Table } 1 . & & \\ & & \\ r_{1}: A_{2} \rightarrow A_{2} r_{5}: A_{3} \rightarrow A_{4} & r_{9}: A_{4} \rightarrow A_{5} r_{13}: A_{6} \rightarrow A_{4} \\ r_{2}: A_{2} \rightarrow A_{7} r_{6}: A_{4} \rightarrow A_{1} r_{10}: A_{5} \rightarrow A_{4} r_{14}: A_{7} \rightarrow A_{5} \\ r_{3}: A_{3} \rightarrow A_{2} r_{7}: A_{4} \rightarrow A_{3} r_{11}: A_{5} \rightarrow A_{5} r_{15}: A_{7} \rightarrow A_{7} \\ r_{4}: A_{3} \rightarrow A_{3} r_{8}: A_{4} \rightarrow A_{4} r_{12}: A_{5} \rightarrow A_{6}\end{array}$

The result shown that CCFI is a long-term significance level oversold phenomenon. This result and its reward scale of the risk increase are related to within the group. We used Table 1 data in our analysis according to the R.M.S.P.E. (root mean square percentage error) method, and the average prediction error is shown to be $0.078 \%$. Through fuzzy time series analysis, the forecasted CCFI and actual CCFI are shown in Figure 2. Based on these fuzzy time series results, it can be estimated that in 2015Q3 the CCFI will average 893.557 level; this forecast is demonstrated in the following diagram (Figure 2).

Since February 2007, after the US subprime mortgage crisis occurred, the US dollar began to depreciate, and the impact extended to the whole world, causing the global financial crisis. This has caused the appreciation of China's currency, and impacted the conditions of China's export shipments. The utilization rate for ship space began to decline, and the CCFI at that time also dropped to its lowest point. In 2010, due to the fact that the impact of the financial tsunami had gradually slowed down, the CCFI index began to rise during the second quarter. In 2011, the world economy began to consolidate, and therefore the CCFI was also affected by the economy in Europe, and it was relatively low. From 2012, the world gradually emerged from the financial tsunami, and Europe and the US began their recovery. During this time, the CCFI began to rise. During the second quarter of 2012, the maximum rate of return was obtained.

It also shows that many countries gradually started to recover. On this issue, the European routes were greatly encouraged, and the recovery improved and the freight cost increased. Subsequent to 2013, as the large-scale vessels entered into the market, the expansion in ship space rapidly increased. Faced with a situation where supply exceeded demand, coupled with the 2015 stock market crash that occurred in China, the freight rate standard for the CCFI has started to decline.

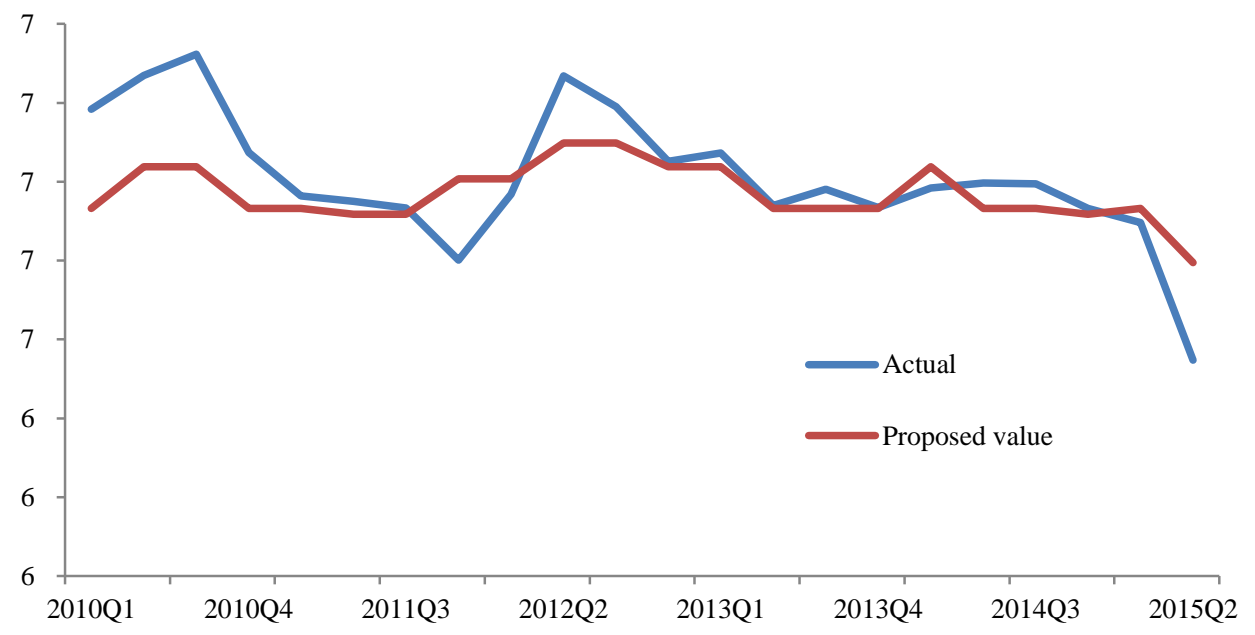

Figure 2. Forecasted CCFI and actual CCFI. 


\section{Conclusion}

In this paper, a long-term predictive value interval model has been developed for forecasting CCFI. This model helps to minimize the uncertainties of fuzzy numbers. The method is examined by forecasting the CCFI using the data from which the min-max interval $(\min , \max )=(6.795,7.098)$ is obtained. As for index returns, the current rate of return is negative, but its volatility is increasing, with fluctuations inside the ( $\min , \max$ ) interval volatility. This phenomenon reflects the China's transformation from world factory to world market; CCFI will thus exhibit less volatility. Due to the ongoing transformation from world factory into world market, we can expect China's CCFI to remain volatile during this interval.

The current model for the CCFI 2012Q3 forecast level is insignificant for the average of 893.557 and within the group mistaken difference does not exceed $1 \%$ of the significance level. Construct a fuzzy time series forecasting model with an CCFI error value less than $1 \%$, with the traditional fuzzy time out in the single-point forecast comparison, this model provides a long-term level and interval analysis. This CCFI research should be able to provide common carrery and Non-vessel Operating Common Carrier with reliable reference data to consider in their Booking Space decisions.

The CCFI is one of the most important container indexes. The index reflects an important indicator for China's shipping market. From the analysis we found that although China's CCFI for shipping standards has been significantly impacted by the global economic crisis, the results of the RMB exchange rate shows that China has aimed to stimulate its sales to Europe, North and South America through the devaluation of the RMB. As a result, the CCFI was impacted. The current CCFI for shipping cost standards is at a low point. The devaluation of the RMB exchange rate is continuing. Current shipping cost standards are experiencing a low-level concussion. In 2015, international oil prices have also been at a low point (Bondia et al., 2016). International oil prices dropped from \$ 100 USD a barrel to \$ 40 USD a barrel. According to the structure of shipping companies, fuel accounts for about 40-50\% of operating costs. Under the combination of these conditions, it is easy to see that China's export situation still has a strong competitive advantage when compared to other countries (Kalgora and Christian, 2016). The CCFI is indeed influenced by the global economy; it is not only influenced by the reduction of international crude oil prices. This decline also coincides with the fact that China's trade and economic growth are impacted by uncertain outcomes, including the devaluation of the RMB. This will affect the overall development of the world economy, and such a concern should not be ignored. If we simply look at the CCFI of freight standards while ignoring the overall devaluation strategy adopted by China, then the trend will lead to global economic concerns.

The analysis also demonstrated that the CCFI is significantly influenced by global economic conditions. Based on CCFI data and yield analysis, it can be observed that currently the yield for freight rate standards is negative. In other words, the current ship supply is beyond the current level of demand. This is a concern for the overall development of the world economy and it cannot be ignored. If we simply look at the CCFI reduction while ignoring the oversupply of ships and the implicit message about management, then the regional economy and the world economy will be affected. As a result, topics on merging of shipping companies must be considered. For example, companies can exchange shipping space and support each other on routes in order to reduce the supply on ships; consequently, the shipping companies will be able to obtain unexpected benefits.

\section{References}

Bondia, R., Ghosh, S., \& Kanijilaf, K. (2016). International crude oil prices and the stock prices of clean energy and technology companies: Evidence from non-linear cointegration tests with unknown structural breaks. Energy, 101, 558-565. http://dx.doi.org/10.1016/j.energy.2016.02.031

Chen, S. H., \& Hsieh, C. H. (2000). Representation, ranking, distance, and similarity of L-R type fuzzy number and application. Australian Journal of Intelligent Information Processing Systems, 6(4), 217-229.

Chen, S. M. (1996). Forecasting enrollments based on fuzzy time series. Fuzzy Sets and Systems, 81(3), 311-319. http://dx.doi.org/10.1016/0165-0114(95)00220-0

Chen, S. M. (2002). Forecasting enrollments based on high order fuzzy time Series. Cybernetics and Systems: An International Journal, 33(1), 1-16. http://dx.doi.org/10.1080/019697202753306479

Chou, M. T. (2008). A fuzzy time series model to forecast the BDI. IEEE Proceeding of the Fourth International Conference on Networked Computing and Advanced Information Management, 50-53. http://dx.doi.org/10.1109/ncm.2008.94

Chou, M. T. (2009). The logarithm function with a fuzzy time series. Journal of Convergence Information Technology, 4(1), 47-51. http://dx.doi.org/10.4156/jcit.vol4.issue1.chou

Chou, M. T. (2011). Long-term predictive value interval with the fuzzy time series. Journal of Marine Science and Technology, 19(5), 509-513. 
Chou, M. T., \& Lee, H. S. (2006). Increasing and decreasing with fuzzy time series. Joint Conference on Information Sciences, 1240-1243. http://dx.doi.org/10.2991/jcis.2006.294

Hsiao, Y. J., Chou, H. C., \& Wu, C. C. (2014). Return lead-lag and volatility transmission in shipping freight market. Maritime Policy and Management, 41(7), 697-714. http://dx.doi.org/10.1080/03088839.2013.865849

Kalgora, B., \& Christian, T. (2016). The financial and economic crisis, its impacts on the shipping industry, lessons to learn: the container-ships market analysis. Open Journal of Social Sciences, 4, 38-44. http://dx.doi.org/10.4236/jss.2016.41005

Lee, H. S., \& Chou, M. T. (2004). Fuzzy forecast based on fuzzy time series. International Journal of Computer Mathematic, 81(7), 781-789. http://dx.doi.org/10.1080/00207160410001712288

Liang, M. T., Wu, J. H., \& Liang, G. S. (2006). Applying fuzzy mathematics to evaluating the membership of existing reinforced concrete bridges in Taipei. Journal of Marine Science and Technology, 8(1), 16-29.

Liaw, M. C. (1997). The order identification of fuzzy time series, models construction and forecasting, Ph.D. Thesis, National Chengchi University, Taiwan.

Shanghai Shipping Exchange. (2015). Retrieved August 10, 2015, website: http:/ http://en.sse.net.cn/.

Song, Q., \& Chissom, B. S. (1993a). Fuzzy time series and its models. Fuzzy Sets and Systems, 54(3), 269-277. http://dx.doi.org/10.1016/0165-0114(93)90372-O

Song, Q., \& Chissom, B. S. (1993b). Forecasting enrollment with fuzzy time series-Part I. Fuzzy Sets and Systems, 54(1), 1-9. http://dx.doi.org/10.1016/0165-0114(93)90355-L

Song, Q., \& Chissom, B. S. (1994). Forecasting enrollment with fuzzy time series-Part II. Fuzzy Sets and Systems, 62(1), 1-8. http://dx.doi.org/10.1016/0165-0114(94)90067-1

Song, Q., Leland, R. P., \& Chissom, B. S. (1997). Fuzzy stochastic time series and its models. Fuzzy Sets and Systems, 88(3), 333-341. http://dx.doi.org/10.1016/S0165-0114(96)00077-2

Xin, S. (2000). The study on the compilation of the China container freight index. Maritime Policy and Management, 27(3), 303-308. http://dx.doi.org/10.1080/030888300411121

Zadeh, L. A. (1965). Fuzzy set. Information and Control, 8(3), 338-353. http://dx.doi.org/10.1016/S0019-9958(65)90241-X

This work is licensed under a Creative Commons Attribution 3.0 License. 